\title{
Improving Strength in Casting Mold by Control of Starting Material and Process
}

\author{
Geun-Ho Cho, Eun-Hee Kim, and Yeon-Gil Jung ${ }^{\dagger}$ \\ School of Materials and Engineering, Changwon National University, Changwon 51140, Korea \\ (Received May 30, 2016; Revised July 21, 2016; Accepted July 22, 2016)
}

\begin{abstract}
In developing high temperature molds with advantages of the sand and precision (investment) castings, mechanical properties of the mold were improved through homogeneous coating of starting powders with an inorganic binder and improvement of fabrication process. Beads with mullite composition were employed for properties of the mold under high temperature, which was compared with artificial sands. Precursors of silica and sodium oxide were used as starting materials for an inorganic binder to achieve homogeneous coating on the starting powders. Strength was enhanced by the glass phase converted from the inorganic binder through heat treatment process. Also, two kinds of process, wet and dry processes, were incorporated to prepare mold specimens. Consequently, fabrication process of the mold with superior strength and high temperature applicability, compared with the previous molds for sand casting, could be suggested through control of the starting material and enhancement of the vitrification efficiency.
\end{abstract}

Key words : Sand mold, Inorganic precursor, Coating, Fracture strength, Vitrification

\section{Introduction}

$\mathrm{A}$ $\mathrm{s}$ a method to fabricate general mechanical parts, sand casting method has been extensively used, while application of precision (investment) casting is being required essentially for fabrication of hollow, complex shapes along with development of industrial technology. ${ }^{1)}$ However, in the existing investment casting process, formed wax models are prepared in a desired form by using an injection machine, followed by production of a wax tree to cast several patterns at one go, and subsequently undergoing slurry coating process, after which ceramic coating (back-up coating) is applied over several times to the thickness larger than a certain value for manifestation of mold strength. In each coating process, dry process is included, and the prepared mold should undergo a series of processes where molten bath of metal is poured and cooled after dissolving wax and residues at an elevated temperature. ${ }^{2-4)}$ In such case of investment casting process, casting is limited to small objects, causing degradation of productivity and increase in casting costs as a multi-stage process.5) Meanwhile, although the sand casting method using organic binders has the advantages of relatively simple processes and low production costs, it has the problems of forming blow holes and having a low dimensional stability due to occurrence of large amounts of gas by use of organic binders, and shrink-

${ }^{\dagger}$ Corresponding author: Yeon-Gil Jung

E-mail : jungyg@changwon.ac.kr

Tel : +82-55-213-3712 Fax : +82-55-262-6486 age flaws as well as dimensional defects are produced in the cast items as a result of insufficient liquidity of molten bath caused by room temperature casting. ${ }^{6-7)}$ In addition, thicknesses of the mold should be increased in proportion to the size to maintain a shape of the mold upon casting as a result of increase in the size of cast articles. ${ }^{8)}$

Meanwhile, as a measure to utilize precision as the advantage of investment casting process, studies on development of high-temperature type molds and cores have been conducted for the conversion process of organic binders and inorganic binders by application of inorganic binders to sand casting processes. ${ }^{3)}$ In previous studies, wet process enabled heat treatment at high-temperature and casting to a thickness smaller than the existing value through organic-inorganic binder conversion processes, while dry process had no loss of inorganic binders due to vaporization of organic binders resulting in display high strengths, and facilitated production of cores having to withstand the load of the molten bath and of large-scale cast items. ${ }^{9-10)}$ However, selection of new starting powders and improvement of strengths are still required by considering limitations in strength manifestation and an increase in production costs due to the high prices of beads (ceramic beads) applied as the starting powder.

Therefore, in the present study, two types of process, wet process and dry process, were incorporated together as a fabrication process to apply inorganic binders in preparing molds by using various starting materials, and strength manifestation was to be realized through process optimization. In the case of starting powders to produce molds, the beads with excellent heat resistance and high-temperature 
characteristics, and artificial sands 5 and 7 having different particle sizes were selected, and composite sand was to be utilized through mixing of the artificial sand with the beads. Meanwhile, thicknesses of the coating layer of glass phase generated on starting powders were to be increased by introducing the repeated coating process of the inorganic binder, and mechanical characteristics were evaluated as functions of securing various corresponding processes and coating frequency of the inorganic binder.

\section{Experimental Procedure}

\subsection{Starting material and fabrication process}

As the starting powders for preparing molds, artificial sands 5 and 7 having different particle sizes (Artificial sand, Namgwang casting materials, Jinhae, Korea) and beads (Cerabead, Itochu, Osaka, Japan) were used individually or by mixing in the ratio of $50: 50 \mathrm{vol} \%$. In the case of mixing, each starting powder underwent dry ball-mill process at room temperature for $3 \mathrm{~h}$ under the speed of $150 \mathrm{rpm}$ by using alumina balls. Upon application of inorganic binders, silica precursor (Tetraethyl orthosilicate: TEOS, SigmaAldrich Korea, Yongin, Korea) and sodium oxide precursor (Sodium methoxide: NaOMe, Sigma-Aldrich Korea, Yongin, Korea) were used as an inorganic binder for homogeneous coating, and isobutyl alcohol (Sigma-Aldrich Korea, Yongin, Korea) was employed as a solvent dissolving the precursors. As the process for fabricating specimens, the wet and dry processes were applied, with the detailed process variables being shown in Table 1. First, in the wet process, specimens were produced by mixing the starting powder and the organic binder (Resin, Kolon Chemical, Korea), with immersion in the inorganic precursor solution for 5 minutes. In the dry process, the starting powder underwent drying process to vaporize the alcohol component mixed in the inorganic precursor after being coated with the inorganic precursor, after which green compacts were produced by mixing $2.34 \mathrm{~g}$ of organic binder (Polyvinyl alcohol: PVA; Sigma-Aldrich Korea, Yongin, Korea) per $100 \mathrm{~g}$ of starting material. Specimens were produced in the size of $10 \times 10 \times 50 \mathrm{~mm}$ through a uniaxial pressurized molding machine (Uniaxial pressing, H4P-5, Hyundai Mechanic \& Electric, Korea), and thus-produced green compacts had the organic binder with a low debinder temperature vaporized in heat treatment process.
The green compacts fabricated by the wet and dry processes underwent drying process at $80^{\circ} \mathrm{C}$ for $24 \mathrm{~h}$ for gelation of the inorganic binder coated onto particles, followed by heat treatment process at $1000^{\circ} \mathrm{C}$ for $1 \mathrm{~h}$, after which specimens for characteristics evaluation were produced. ${ }^{11)}$ Also, to additionally enhance strengths in the wet process, specimens were produced for characteristics evaluation by incorporating the process where immersion and drying processes were extended repeatedly up to 4 times.

\subsection{Characteristics evaluation}

For the heat-treated specimens, fracture strengths were measured by using a universal tester (Universal Testing Machine; UTM, Instron 5566, Instron Corp., Norwood, MA, USA), where the measurement conditions for fracture strength involved crosshead speed of $0.5 \mathrm{~mm} / \mathrm{min}$ at span distance of $40 \mathrm{~mm}$ by using 3-point bending strength method, and strength values were measured for more than 5 specimens as the minimum. Microstructures for the specimens before and after heat treatment were observed by using a scanning electron microscope (SEM, JEOL Model JSM-5610, Tokyo, Japan), while element analysis of the glass phase formed after heat treatment in the specimens was performed for each condition by using an X-ray spectrometer (Energy resolution $133 \mathrm{eV}$; Oxford Instruments, Oxford, UK). Phase analysis for the starting powders was conducted through an X-Ray Diffractometer (XRD; Philips X-pert MPD, Model PW3040, Eindhoven, Netherlands). Also, dimensional stability of the specimens resulting from application of inorganic binders was evaluated by measuring dimensional changes in the specimens before and after heat treatment.

\section{Results and Discussion}

\subsection{Characteristics and combination ratios of starting powder}

Observation results on particle shapes in the starting powders are shown in Fig. 1. As can be affirmed in Fig. 1, the bead particles show an average particle size of $150 \mu \mathrm{m}$ with a spherical form, while the particle shape of artificial sand is shown as irregular polygonal form. In general, artificial sand 7 consists of particles having a similar size to that of bead, while artificial sand 5 consists of particles of a

Table 1. Basic Formulations for Preparing Mold Specimens with Various Starting Powders

\begin{tabular}{clll}
\hline Run & Starting powder & Inorganic precursor $(\mathrm{g})$ & Process \\
\hline Run 1 & Artificial sand 5 & Wet Process \\
Run 2 & & & Dry Process \\
Run 3 & Artificial sand 7 & TEOS (38) & Wet Process \\
Run 4 & & NaOMe (56) & Dry Process \\
Run 5 & Artificial sand $7+$ Bead & BuOH (6) & Wet Process \\
Run 6 & (50:50 vol $\%)$ & & Dry Process, $24 \mathrm{~h}$ \\
Run 7 & Cerabead & & Wet Process heat treatment: \\
Run 8 & & & Dry Process \\
\hline
\end{tabular}



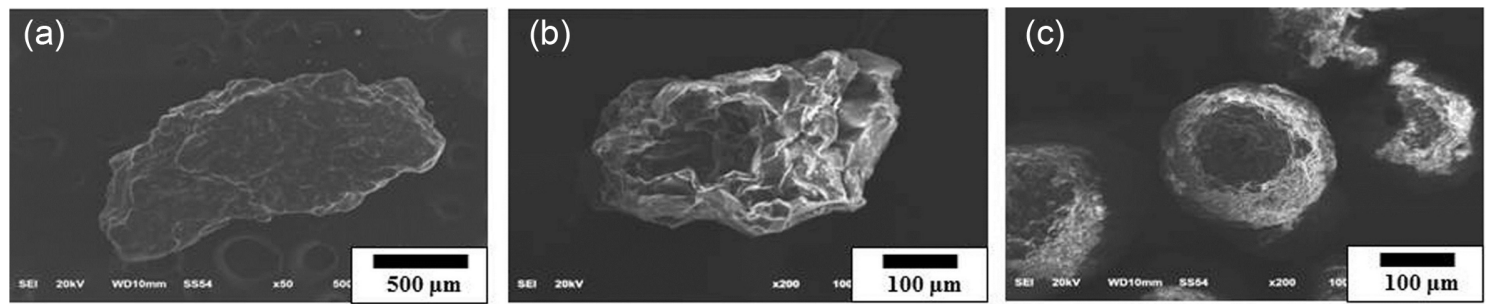

Fig. 1. Morphology of starting powders used in this study: (a) artificial sand 5, (b) artificial sand 7, and (c) Cerabead.

larger size than that of bead. Based on the previous study where the lower strength characteristics were exhibited, the larger the particle size of starting material, ${ }^{12)}$ mixture of artificial sand 7 and bead was employed together as a starting powder to manifest the effect of saving production costs while maintaining the characteristics. When compared with bead particles where the peaks of mullite composition (ICSD : 98-006-6452) in Fig. 2(c) appeared in the phase analysis result for the starting material of Fig. 2, the peaks of silica composition (ICSD : 98-016-8354) can be affirmed in artificial sand 5 of Fig. 2(a) and artificial sand 7 of Fig. 2(b). Since the artificial sand 7 has a composition of silica while having a size similar to that of bead based on this observation accompanied by a relatively high price, the production costs could be lowered while mechanical characteristics are maintained if the bead with regeneration process being essential through sand removal after casting is replaced or use is made of mixing with the bead. ${ }^{13)}$

\subsection{Mechanical characteristics through vitrifica- tion conversion process}

The results of strength characteristics for the mold specimens produced by the wet and dry processes using an inorganic precursor are shown in Fig. 3. In all specimens, strength values after heat treatment could be affirmed to be improved as compared with the values before heat treatment. This shows the result of improving bonding forces between particles as the inorganic precursor is converted to

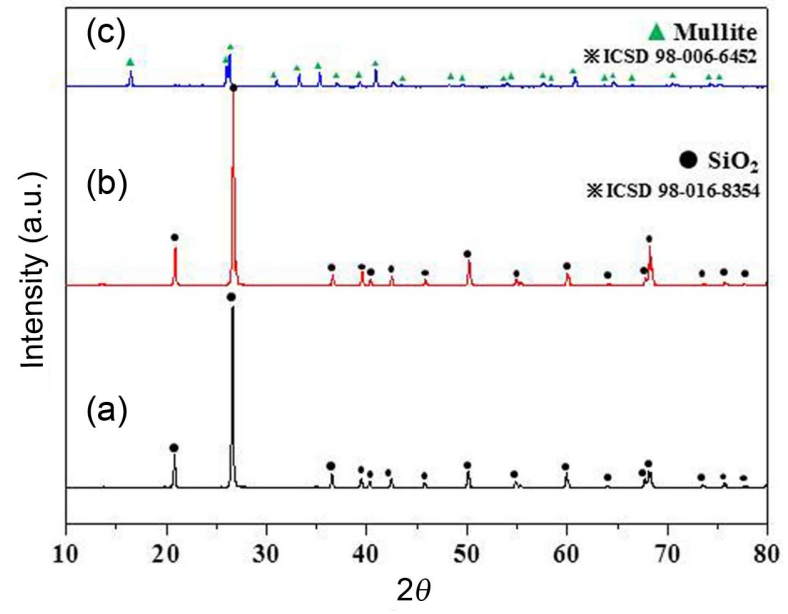

Fig. 2. XRD results of starting powders: (a) artificial sand 5, (b) artificial sand 7, and (c) Cerabead. a glass phase during heat treatment. In the case of dry process, high strength values with the maximum of $12.3 \mathrm{MPa}$ were observed in the bead (Run 8), and a strength value of 8.7 MPa was observed in the case of artificial sand 7 (Run 4). In the case of specimen produced by mixing of bead and artificial sand in the ratio of $50: 50 \mathrm{vol} \%$, a strength value of 9.3 MPa was observed (Run 6), showing a higher strength value than the specimen with application of artificial sand 7 only. Hence, it is considered that economy of artificial sand and advantages of bead having excellent characteristics in heat resistance and thermal expansion can be converged.

Meanwhile, in the case of artificial sand 5, quite low strength values (1.4 MPa (Run 1) for wet process and 5.5
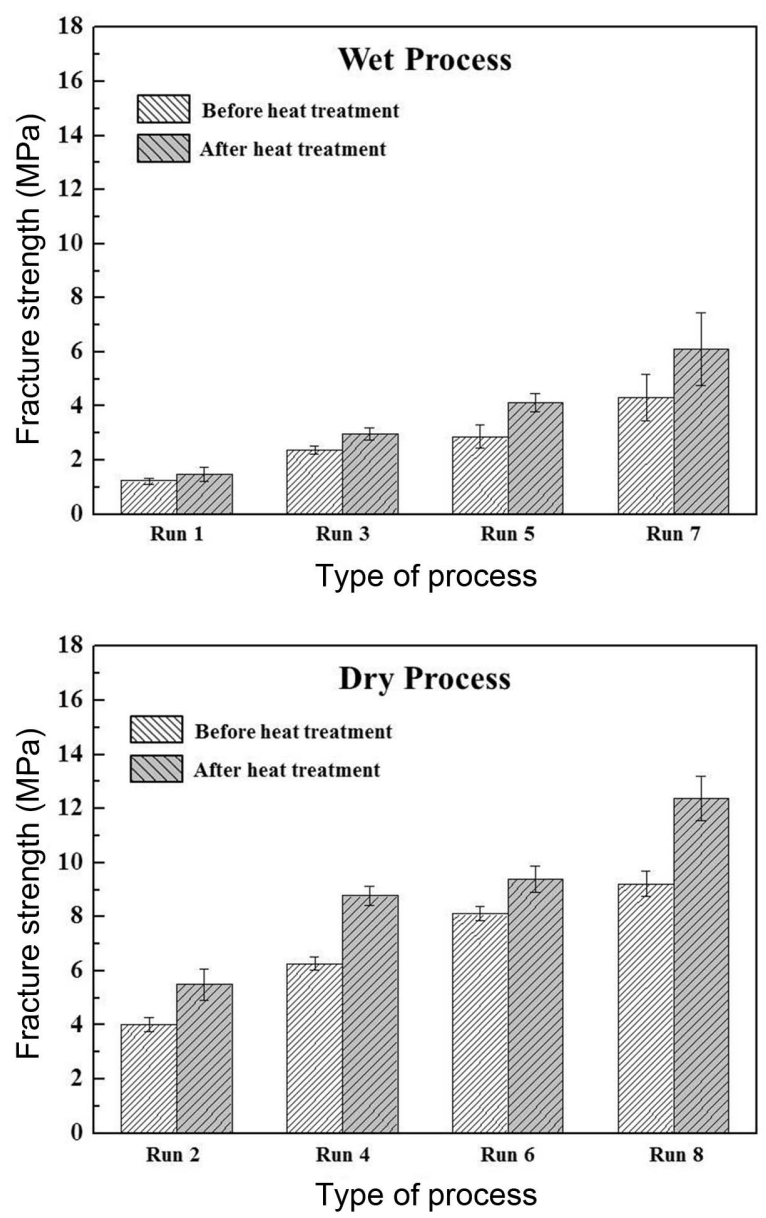

Fig. 3. Fracture strength values of mold specimens prepared by the wet and dry processes. 
(a)

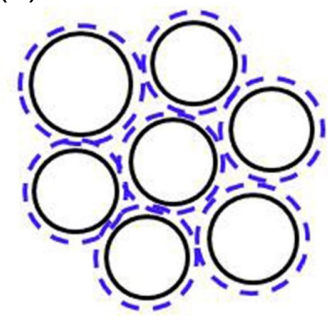

(b)

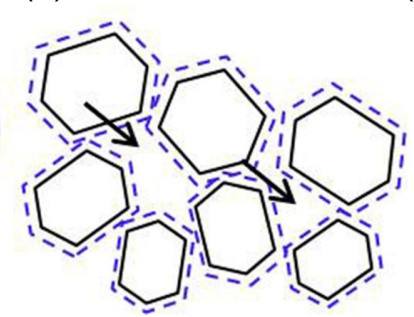

(c)

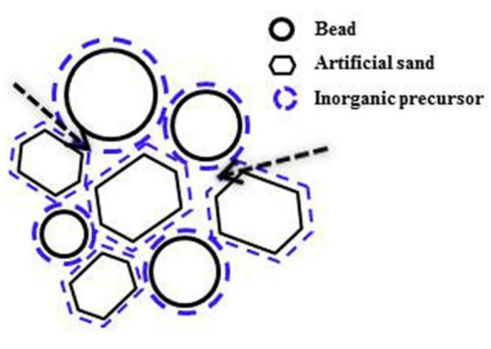

Fig. 4. Schematic diagram for strength development in each specimen during heat treatment: (a) Cerabead, (b) artificial sand, and (c) composite sand (Cerabead + artificial sand 7).

MPa (Run 2) for dry process) were exhibited, and somewhat lower strength values (2.9 MPa (Run 3) for wet process and 8.7 $\mathrm{MPa}$ (Run 4) for dry process) compared with those for bead could also be affirmed in the case of artificial sand 7 . To consider the mechanism for strength manifestation as functions of starting powder and process, schematic diagrams for bead, artificial sand, and composite body coated with inorganic binder as a result of heat treatment process are shown in Fig. 4. Since generation of the glass phase inducing the enhancement strengths of molds in the wet and dry processes exhibits the highest effects when it is formed between starting particles, the strength can be seen to be affected by size and distribution of the starting particles as well as the particle shape. Since the artificial sand has inhomogeneous polygonal forms which causes a low packing factor and increased pores (solid line arrow part) upon production of green compacts, and amounts of the inorganic binder converted at interfaces are small due to reduction of contact areas between particles lower strength characteristics are observed as compared with the bead. In the case of bead, the packing factor is relatively high as it has a spherical form, and hence pores between particles are small and contact areas between particles with coating of an inorganic binder are large so that strengths can be mani-

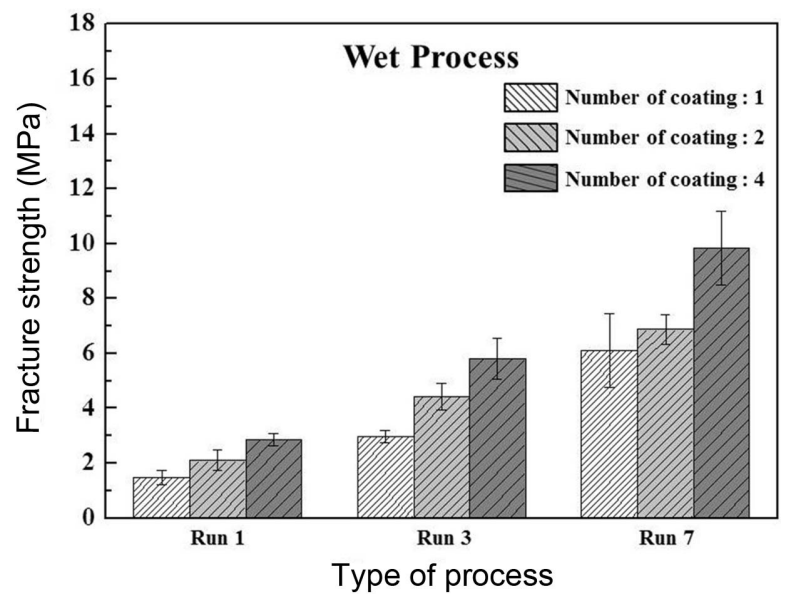

Fig. 5. Fracture strength values of mold specimens prepared by wet process. Run 1, Run 3, and Run 7 indicate artificial sand 5, artificial sand 7, and Cerabead, respectively. fested due to glass phase formed at particle interfaces during heat treatment. Meanwhile, when the specimens were produced by homogeneous mixing of bead and artificial sand, artificial sand of inhomogeneous polygonal forms is mixed so that more pores can be formed compared with the case where only bead was used. However, since the contact areas between particles are larger than those for the case where only artificial sand is used (dotted line arrow part), strength can be enhanced.

For strength improvement in the wet process showing slightly lower strength vales compared with the dry process, the effects of coating frequency of inorganic binder on strength were considered, and the results are shown in Fig. 5. As a result, the increase in strength with an increase in coating frequency could be affirmed when compared with the case where inorganic binder was coated only once (i.e., when immersed once in the inorganic binder solution). In the case of bead (Run 7), the strength value of $6.1 \mathrm{MPa}$ as the result of coating for once was increased to 9.8 MPa upon coating for 4 times, and no further increase in strength was observed in the case of coating for more than 4 times. Namely, for the increase in coating frequency beyond 4 times, it could be affirmed that no more coating of inorganic binder on pores or interfaces between particles inside specimens was realized. When the coating frequency for inorganic precursor is increased, the amount of glass phase in heat treatment is increased resulting in improvement of strength characteristics by increasing the amount of inorganic binder at the interface between particles or in uncoated parts. As can be observed from a picture of the fractured surface (Fig. 6) after strength measurement for the specimens produced by wet process, the center region of artificial sand 7 did not react upon coating of inorganic binder for once (arrow part in Fig. 6(a)), while reaction only in the surface part was affirmed in the case of bead (arrow part in Fig. 6(b)). As the reaction layer becomes thicker with an increase in coating frequency, homogenization of the reaction up to inside of the specimens can be affirmed and sufficient strength manifestation could be seen. Therefore, higher strength values than $7 \mathrm{MPa}$ known to be the typical strength value for the existing sand casting could also be secured in wet process through an increase in coating frequency. ${ }^{14)}$

Microstructure observation and element analysis were 


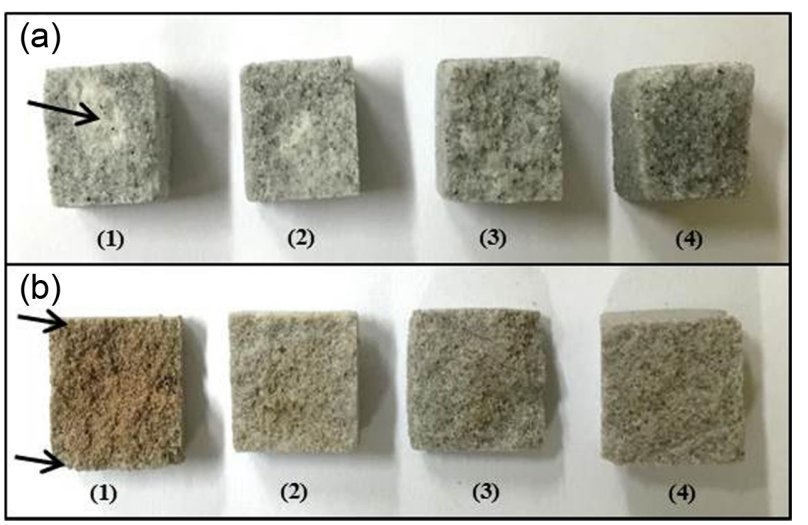

Fig. 6. Fracture surface of mold specimens prepared by wet process: (a) artificial sand 7 and (b) Cerabead. Each number indicates the number of coating. The unreacted area for artificial sand 7 and the reacted area for Cerabead are indicated with arrows in figures A and $\mathrm{B}$, respectively.

performed to investigate the cause for strength manifestation, and the results are shown in Fig. 7. First, in the case of element analysis, since the point analysis method was adopted to identify whether the particles were uniformly coated with inorganic binder, detection of $\mathrm{Na}$ composition could be affirmed in the inorganic binder composition due to addition of sodium oxide for all specimens using artificial sand and bead although no tendency was displayed. Through this observation, it could be seen that inorganic binder had been uniformly coated on the particle surfaces by enhancing the liquidity of silica (solid line arrow part). In Fig. 7(d) showing the microstructure of both specimens prepared by the wet and dry processes using artificial sand 5 as the starting powder having a relatively large particle size, relatively large pores could be affirmed due to shape inhomogeneity of the starting particles (dotted line arrow part). However, in the specimens prepared with artificial sand 7 (Fig. 7(a)), bead (Fig. 7(b)), and mixture of bead and artificial sand 7 (Fig. 7(c)), the conversion of inorganic binder to a glass phase on the interfaces of particles can be affirmed. Heat treatment was conducted at $1000^{\circ} \mathrm{C}$ for $1 \mathrm{~h}$, as a process intended to generate the glass phase on the particle surfaces. Strength of a mold is manifested by generation of the glass phase, and the efficiency is reduced as no conversion to the glass phase occurs when temperatures are too low and the glass phase is decomposed when temperatures are too high. ${ }^{15)}$

\subsection{Observation of dimensional changes resulting from heat treatment for investment casting}

In the investment casting, the mold should maintain its shape for a relatively long time (until metal is completely

Wet Process

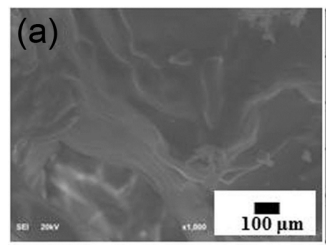

\begin{tabular}{|c|c|}
\hline Element & $\mathbf{W t} \%$ \\
\hline $\mathbf{O}$ & 54.29 \\
\hline $\mathbf{N a}$ & 6.31 \\
\hline $\mathbf{S i}$ & 39.40 \\
\hline Total: & 100.00 \\
\hline
\end{tabular}

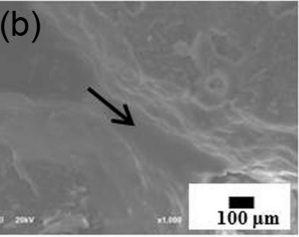

\begin{tabular}{|c|c|}
\hline Element & $\mathbf{W t} \%$ \\
\hline $\mathbf{O}$ & 51.11 \\
\hline $\mathbf{N a}$ & 11.40 \\
\hline $\mathbf{S i}$ & 37.49 \\
\hline Total: & 100.00 \\
\hline
\end{tabular}

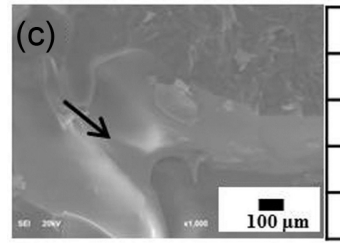

\begin{tabular}{|c|c|c|}
\hline Element & Wt\% & (d) \\
\hline $\mathbf{O}$ & 62.05 \\
\hline $\mathbf{N a}$ & 13.15 \\
\hline $\mathbf{S i}$ & 24.80 \\
\hline Total: & 100.00 \\
3
\end{tabular}$\quad$\begin{tabular}{c} 
\\
$\mathbf{1 0 0} \mu \mathrm{m}$ \\
\hline
\end{tabular}

\begin{tabular}{|c|c|}
\hline Element & Wt\% \\
\hline $\mathbf{O}$ & 59.36 \\
\hline $\mathbf{N a}$ & 1.73 \\
\hline $\mathbf{S i}$ & 38.91 \\
\hline Total: & 100.00 \\
\hline
\end{tabular}

Dry Process

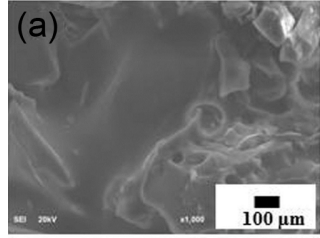

\begin{tabular}{|c|c|}
\hline Element & $\mathbf{W t} \%$ \\
\hline $\mathbf{O}$ & 61.40 \\
\hline $\mathbf{N a}$ & 10.65 \\
\hline $\mathbf{S i}$ & 27.95 \\
\hline Total: & 100.00 \\
\hline
\end{tabular}

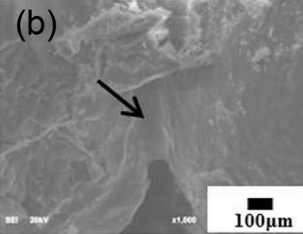

\begin{tabular}{|c|c|}
\hline Element & $\mathbf{W t} \%$ \\
\hline $\mathbf{O}$ & 41.77 \\
\hline $\mathbf{N a}$ & 1.42 \\
\hline $\mathbf{S i}$ & 56.81 \\
\hline Total: & 100.00 \\
\hline
\end{tabular}

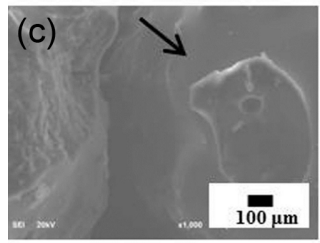

\begin{tabular}{|c|c|}
\hline Element & $\mathbf{W t} \%$ \\
\hline $\mathbf{O}$ & 60.46 \\
\hline $\mathbf{N a}$ & 13.09 \\
\hline $\mathbf{S i}$ & 26.45 \\
\hline Total: & 100.00 \\
\hline
\end{tabular}

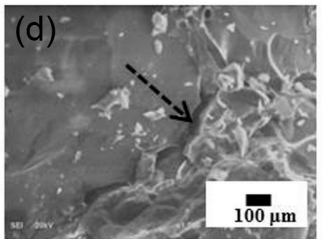

\begin{tabular}{|c|c|}
\hline Element & $\mathbf{W t} \%$ \\
\hline $\mathbf{O}$ & 48.27 \\
\hline $\mathbf{N a}$ & 4.14 \\
\hline $\mathbf{S i}$ & 47.59 \\
\hline Total: & 100.00 \\
\hline
\end{tabular}

Fig. 7. Microstructure of fracture surface and results of element analysis for mold specimens prepared with various starting powders: (a) artificial sand 7, (b) Cerabead, (c) composite powder (Cerabead + artificial sand 7), and (d) artificial sand 5. Solid and dotted lines indicate the glass phase and pores created between particles, respectively. 

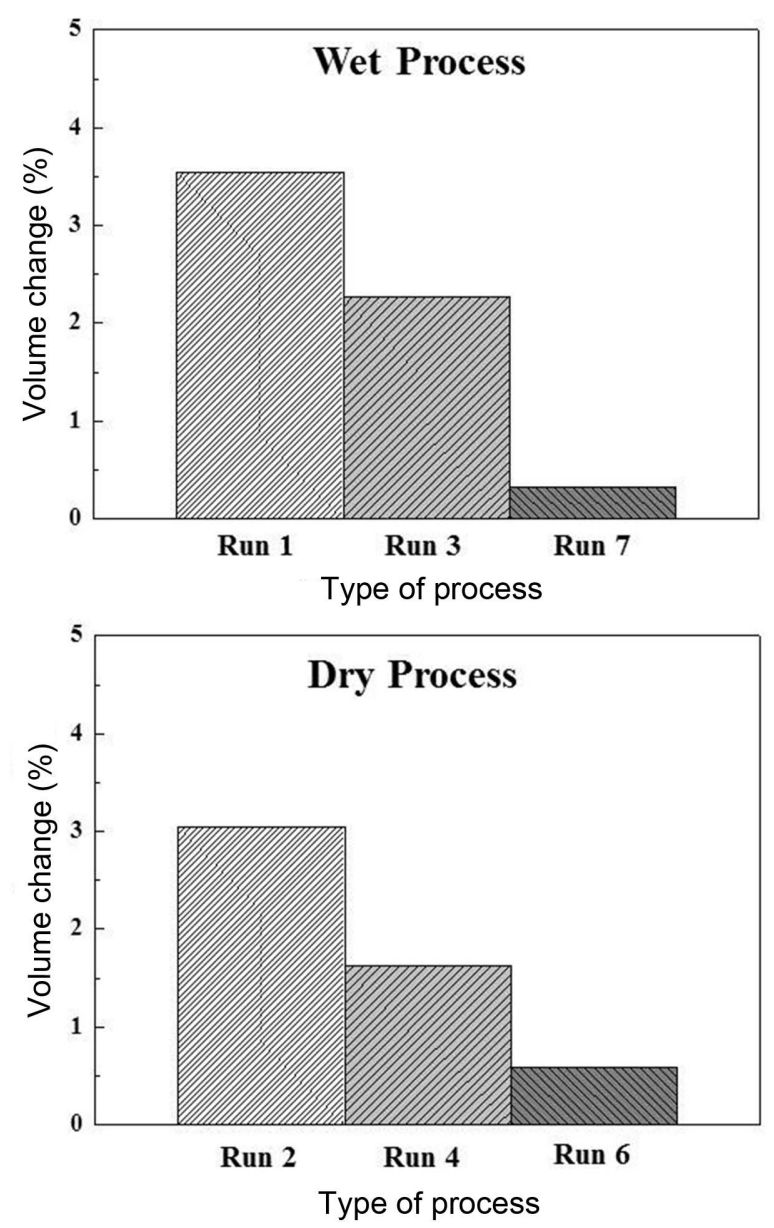

Fig. 8. Dimensional change of mold specimens prepared by the wet and dry processes.

solidified), for which the control of dimensional changes resulting from heat treatment is required. For application of the mold produced by the developed process to the investment casting process, specimens were prepared by using bead and artificial sand, and its dimensional changes in the specimens before and after heat treatment were shown in Fig. 8. The largest change in both processes was observed in the specimens prepared from artificial sand 5 (3.5\% for wet process (Run 1) and 3.1\% for dry process (Run 2)). In artificial sand 7, the change ratios of $2.3 \%$ (Run 3 ) and $1.6 \%$ (Run 4) were observed for the wet and dry processes, respectively, while the smaller dimensional changes of $0.3 \%$ (Run 7) and $0.6 \%$ (Run 8) could be affirmed for the wet and dry processes, respectively, in the case of bead. Whereas somewhat larger changes could be affirmed for wet process in the case of artificial sand, relatively larger changes occurred for dry process in the case of bead so that the effects of process on the dimensional stability of the specimens were generally observed to be incomplete. Consequently, almost no dimensional changes were observed after heat treatment when a mold was fabricated using bead as the starting material, allowing manifestation of dimensional stability. Also, in the case of artificial sand 7, the amount of change was not gen- erally large either although relatively large changes were observed in the specimen with artificial sand 7 than bead. Hence, cast items could be fabricated smoothly by applying the molds prepared by artificial sand 7 .

\section{Summary}

In the present study, starting powder and fabrication process were controlled for characteristics improvement in high-temperature type molds which would allow production of cast articles with hollow, complex shapes along with dimensional stability, and the corresponding effects on mechanical characteristics of molds were discussed. From which the following conclusions have been derived.

1) As the size of starting powder is reduced and the packing factor among particles is increased, the amount of inorganic binder coated on the interface between particles is increased, ultimately improving the strength of mold owing to an increase in glass phase during heat treatment. Wet process applied in this study showed mean strength values of 1.4 $\mathrm{MPa}$ in the case of artificial sand 5, 2.9 MPa in the case of artificial sand 7, 6.1 MPa in the case of bead, and 4.1 MPa in the case of mixture of artificial sand and bead in the ratio of $50: 50$ vol\%.

2) In the case of mold specimens produced by dry process, relatively large strength values were displayed due to the improved efficiency of vitrification resulting from the subsequent heat treatment as the starting powder was directly coated with inorganic binder. Dry process applied in this study showed mean strength values of 5.5 MPa in the case of artificial sand 5, 8.7 MPa in the case of artificial sand 7, 12.3 $\mathrm{MPa}$ in the case of bead, and 9.3 MPa in the case of mixture of artificial sand and bead in the ratio of $50: 50 \mathrm{vol} \%$.

3) In wet process, the contents of inorganic binder coated on the surfaces and interfaces of particles could also be increased through repeated coating of inorganic binder. As the coating frequency was increased from once to 4 times, the mean strength values of $2.8 \mathrm{MPa}$ for artificial sand 5, $5.8 \mathrm{MPa}$ for artificial sand 7 , and $9.8 \mathrm{MPa}$ in the case of bead were observed.

4) In both the wet and dry processes, the largest dimensional changes of $3.1 \sim 3.5 \%$ occurred in the case of artificial sand 5 , and the dimensional changes of $1.6 \sim 2.4 \%$ were observed for artificial sand 7, while the smallest dimensional changes of $0.3 \sim 0.6 \%$ were exhibited in the case of bead. Through this observation, when the inorganic binder process is incorporated, it could be seen that the strength and the dimensional stability could also be secured even when artificial sand 7 was used in combination or by itself for production of casting molds.

\section{Acknowledgments}

The present article has resulted from the study performed under the support of 2015 2016 research funds for autonomous study project by Changwon National University. 


\section{REFERENCES}

1. K. H. Lee, T. K. Kim, and T. Y. Na, "The Status of Domestic Investment Casting Industry (in Korean)," J. Kor. Found. Soc., 12 [2] 125-30 (1992).

2. Y. G. Im, S. I Chung, and H. D. Jeong, "Development of Investment Casting Technique using R/P Master Model (in Korean)," Korean Soc. Precis Eng., 16 [6] 52-7 (1999).

3. Y. A. Meng and B. G. Thomas, "Modeling Transient Slaglayer Phenomena in The Shell/Mold Gap in Continuous Casting of Steel," Metall. Mater. Trans. B, 34 [B] 707-25 (2003).

4. M. Simsir, L. C. Kumruoglu, and A. Ozer, "An Investigation into Stainless-Steel/ Structure-Alloy-Steel Bimetal Produced by Shell Mould Casting," Mater. Des., 30 264-70 (2009).

5. S. K. Kim and M. K. Kim, "A Study on the Precision Casting Method of Urea (in Korean)," Korean Soc. Manuf. Process. Eng., 3 205-10 (2004).

6. B. W. Kim, "Blowholes, Pinholes, Slag Inclusion, Chiled Edges (in Korean)," J. Kor. Found. Soc., 9 [6] 446-53 (1989).

7. R. Rajkolhe and J. G. Khan, "Defects, Cause and Their Remedies in Casting Process: A Review," Int. J. Res., 2 [3] 375-83 (2014).

8. S. Koroyasu, "Effect of Coat on Cooling Capacity of Mold in
Evaporative Pattern Casting Process (in Korean)," J. Kor. Found. Soc., 25 [5] 190-94 (2005).

9. E. H. Kim, W. R. Lee, Y. G. Jung, and C. S. Lee, "A New Binder System for Preparing High Strength Inorganic Molds in Precision Casting," Mater. Chem. Phys., 126 34451 (2011).

10. E. H. Kim, G. H. Jo, J. H. Lee, Y. G. Jung, J. H. Ha, and U. G. Paik, "Powder Preparation for a Shell Mold Using a New Coating Process," Ceram. Int., 38 2749-55 (2012).

11. E. H. Kim, J. H. Lee, Y. G. Jung, C. S. Lee, and Y. G. Paik, "A New in Situ Process in Precision Casting for Mold Fabrication.” J. Eur. Ceram. Soc., 31 1581-88 (2011).

12. G. H. Cho, J. Li, E. H. Kim, and Y. G. Jung, "Preparation of a Ceramic Core with High Strength using an Inorganic Precursor and the Gel-Casting Method," Surf. Coat. Technol., 284 396-99 (2015).

13. S. W. Lye, H. S. Aw, and S. G. Lee. "Adhesives for Bead Fusion of Recycled Expandable Polystyrene," J. Appl. Polym. Sci., 86 [2] 456-62 (2002).

14. N. Sasaki, "A Revolutionary Inorganic Core and Mold Making Process," Foundry Manage. Technol., 137 [2] 21-5 (2009).

15. P. G. Shewmon, Diffusion in Solids; Vol. 1, pp. 62-6, McGraw-Hill, New York, 1963. 